\title{
Postdiscrimination generalization as a function of testing procedure: Steep inhibitory gradients
}

\author{
JACQUELINE M. DAWLEY and M. RAY DENNY \\ Michigan State University, East Lansing, Michigan 48823
}

\begin{abstract}
Three pigeons received interdimensional discrimination training to criterion. With responses to other test stimuli always reinforced during testing, gradients around S+ were inverted v-shaped (exictatory) when S+ responding was reinforced, steep and v-shaped (inhibitory) when S+ responding was nonreinforced, and very steep and $v$-shaped when $\mathrm{S}+$ responding was both nonreinforced, and punished with a 7 -sec S- presentation.
\end{abstract}

Hearst, Besley, and Farthing (1970), using a resistance to reinforcement procedure in which responses were nondifferentially reinforced during generalization testing around $\mathrm{S}-$, have obtained relatively sharp inhibitory gradients that often lasted over several testing sessions. The present study was concerned with using a resistance to reinforcement procedure for repeated testing of generalization around $\mathrm{S}+$ instead of $\mathrm{S}-$. In addition, the effect of (a) nonreinforcing, and (b) both nonreinforcing and punishing $\mathrm{S}+$ responses with an $\mathrm{S}-$ presentation was assessed during repeated generalization testing. These effects pertained largely to the steepness and direction of the obtained gradients.

\section{METHOD}

\section{Subjects}

Three approximately 6-year-old experimentally naive female White Carneaux pigeons were maintained at $80 \%$ of ad lib weight for the duration of the study.

\section{Apparatus}

A standard operant chamber with an automatic food hopper fitted with two response keys was used. The right key only was used. Total session time and total responses to each stimulus were automatically recorded by clock and counters for each session.
}

\section{Procedure}

Prior to discrimination training, each $S$ received three 75-reinforcement VI 30-sec sessions to stabilize VI responding. Each $S$ then received discrimination training with a 555-nm light as $\mathrm{S}+$ and a white vertical line on a dark surround as $\mathrm{S}-$. The discriminative stimuli were presented equally often in a predetermined manner for variable durations (mean $=30 \mathrm{sec}$ ). $\mathrm{S}+$ responding was reinforced on a VI $30-\mathrm{sec}$ schedule by a $3-\mathrm{sec}$ access to a food hopper. No reinforcement was delivered for $S$ responding. Discrimination training for each $\mathrm{S}$ continued until a criterion ratio $(\mathrm{S}-$ responses/S+ responses $\mathrm{x} 100)$ of $4 \%$ was reached, per Hearst et al (1970).

Three different conditions were used to test for generalization to $\mathrm{S}+$. Each $\mathrm{S}$ was tested under all three procedures but each in a different order. After testing on a given condition, $\mathrm{S}$ received training until discrimination again reached criterion. In Condition I, S+ and 501, 538,576, and $601 \mathrm{~nm}$ were presented in random order for a variable $30 \mathrm{sec}$. Responding to each of the stimuli was reinforced on VI $30 \mathrm{sec}$. Condition II was the same as the first, except that responding to $\mathrm{S}+$ was not reinforced.
Condition III was also the same as the first, except that responding to $\mathrm{S}+$ was both nonreinforced and followed after every response by a 7-sec presentation of $S-$. This punishment procedure did not affect the length of time $S+$ was on for that VI 30-sec occasion. S+ was always presented for the full time scheduled before another stimulus was presented.

Each session under all testing conditions consisted of 12 presentations of each stimulus, and there were four sessions under each testing condition. The interstimulus interval during all sessions was $5 \mathrm{sec}$.

\section{RESULTS AND DISCUSSION}

When Condition I, in which responding to all stimuli was reinforced on a VI $30-\mathrm{sec}$ schedule, was the first condition that $\mathrm{S}$ was tested under, the gradients were the customary inverted v-shaped excitatory gradient (see Fig. 1), as found with the resistance to extinction method of Guttman and Kalish (1956). As shown in Fig. 1, the gradients became flatter with later testing but held up well until the fourth session in which maximum responding no longer occurred at $\mathrm{S}+$.

Under Condition II, in which responding to $\mathrm{S}+$ was nonreinforced and responding to all other test stimuli was reinforced on VI $30 \mathrm{sec}$, the gradients for all $3 \mathrm{Ss}$ tended to be v-shaped or inhibitory around the original $\mathrm{S}+$, especially after the first session. Figure 2 shows the steep gradients obtained with Pigeon 10, in which the effects were most noticeable. Here, it can be seen that the tails of the gradients take the slope of the excitatory gradient as often as they do the inhibitory gradient. But minimal responding always occurred at the original $\mathrm{S}+$. This change in direction of the gradient seems similar to the "flop-over" effect observed late in testing by Hearst et al (1970) in many of their Ss when all stimuli including the original $\mathrm{S}$ - were reinforced during repeated generalization testing, except of course that the switch was in the opposite direction.

The gradients obtained under Condition III, in which responding to $\mathrm{S}+$ was both nonreinforced and punished by a 7 -sec presentation of $S-$ while responding to all other test stimuli was reinforced on VI $30 \mathrm{sec}$, were also 
CONOITION I (Responses to all stimull roinforced on VI 30")

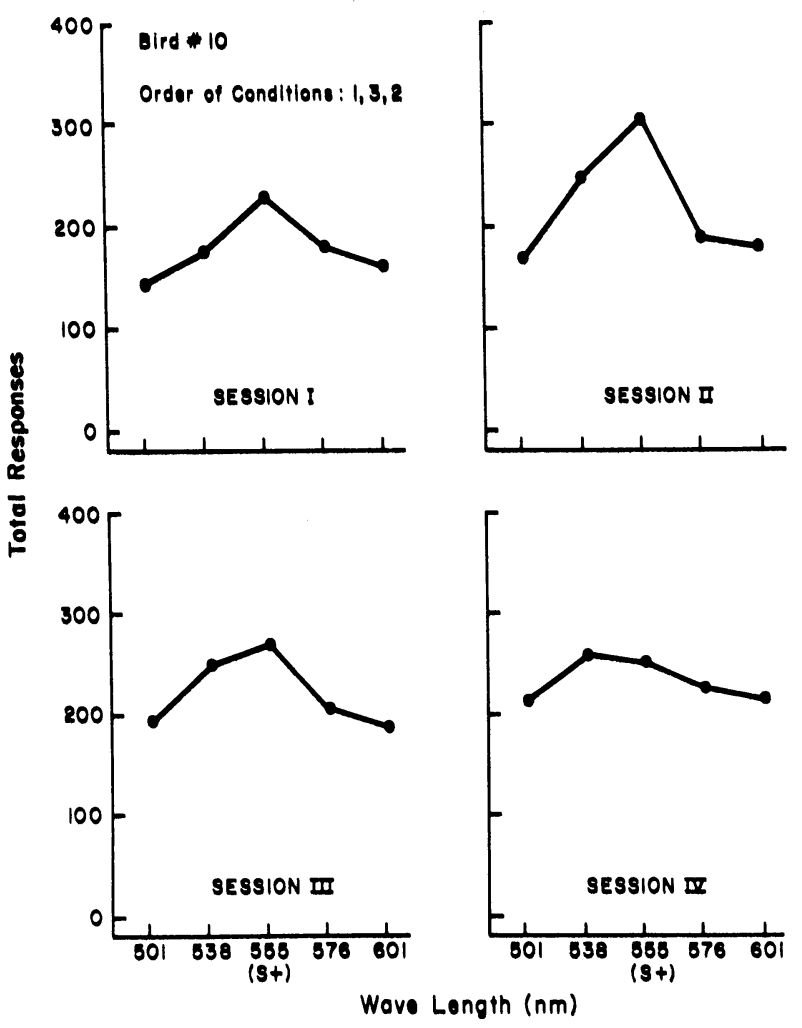

Fig. 1. Generalization gradients generated when responding to all stimuli is reinforced on VI $30 \mathrm{sec}$ and this condition of testing comes first.

inhibitory for all 3 Ss (see Fig. 3). In Condition III, the tails of the gradients all attained the slope of an inhibitory gradient by the fourth session, but this cannot be seen in Fig. 3 because the gradient there is based on all sessions combined. Also, in the later sessions, responding to the original $\mathrm{S}+$ nearly reached zero; that is, the gradients under Condition III seem to be even steeper than those obtained under Condition II.

When Condition I was preceded by Conditions II or III, the results were quite different than when Condition I, as described earlier, came first. The representative gradients presented in Fig. 4 indicate that the inhibition acquired by the original $\mathrm{S}+$ under Conditions II and III persisted even though the original interdimensional discrimination had again reached criterion prior to testing under Condition I, and persisted throughout all four sessions of Condition I for Pigeon 1720 even though all responding was reinforced on VI $30 \mathrm{sec}$ throughout testing. Although the data are not presented here, the presence of persisting inhibition at $\mathrm{S}+$ was also indicated by the fact that the inhibitory gradients for Condition II were steeper in the two cases when Condition II directly followed Condition III, than when the gradient for Condition II was determined first.

The results indicate that a resistance to reinforcement
CONDITION II (Responses to 555 extinguished; all others reinforced)

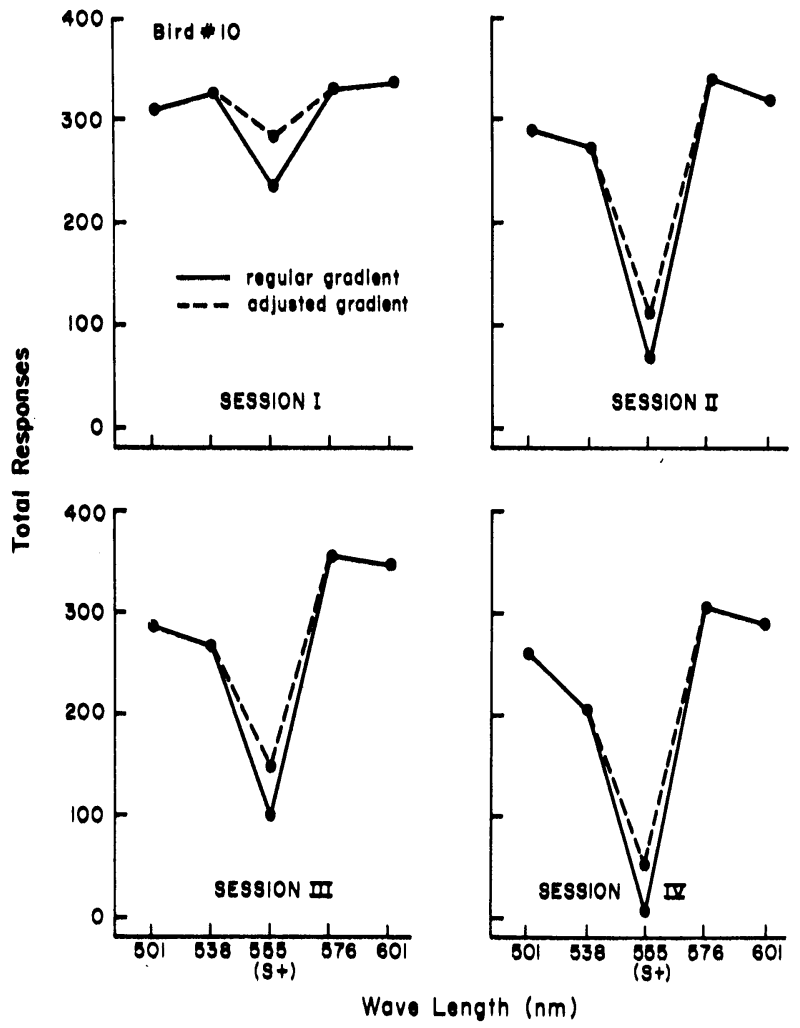

Fig. 2. Generalization gradients typically generated when responding to all stimuli except $S+$ is reinforced in VI $30 \mathrm{sec}$, as shown in Pigeon 10.

\section{CONDITION III (All R's reinforced except those to $S+$, which are also punished by 7 sec. of $S-1$}

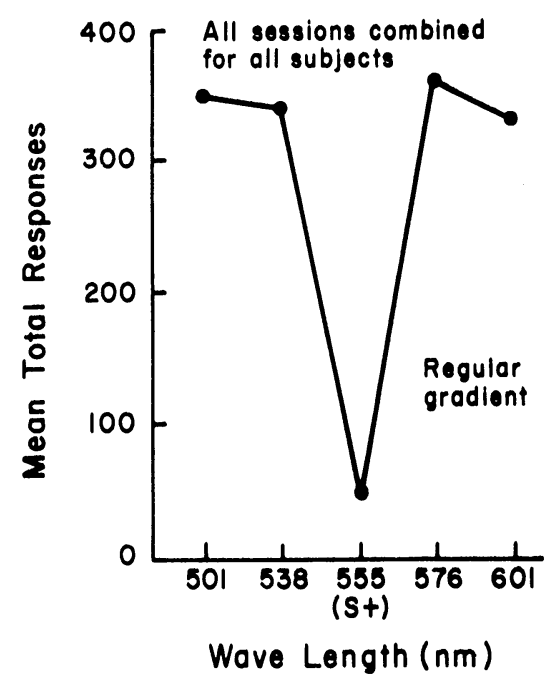

Fig. 3. The generalization gradient generated for all three Ss when responding to $S+$ is both nonreinforced and punished by $7 \mathrm{sec}$ of $\mathrm{S}-$, and all other responding is reinforced on VI $30 \mathrm{sec}$. 
technique can yield positive excitatory gradients that do not quickly disappear with repeated testing. This finding suggests the possibility of obtaining a relatively "pure" stimulus generalization gradient by averaging two gradients-one obtained by the resistance to extinction method and the other by the resistance to reinforcement method-preferably determined in separate groups, with an adjustment for level of responding, if needed.

The results also show that the steepness and direction of generalization gradients are very sensitive to the testing procedure used, and suggest that a good way to produce a steep inhibitory gradient might be in the context of generalization testing in which an original S+ is nonreinforced and all other stimuli are reinforced (like a reversal learning paradigm). Such a procedure, of course, exaggerates the steepness by virtue of the fact that the stimuli adjoining the inhibitory stimulus (original $\mathrm{S}+$ ) are also being reinforced.

It would seem possible to adjust the gradient by removing this factor when a good estimate of the excitatory gradient exists for the same S. This is theoretically the case for Pigeon 10, since Condition I came first. For illustrative purposes, it can be argued, for Pigeon 10, that the degree to which the points on either

CONDITION I (All responses reinforced)

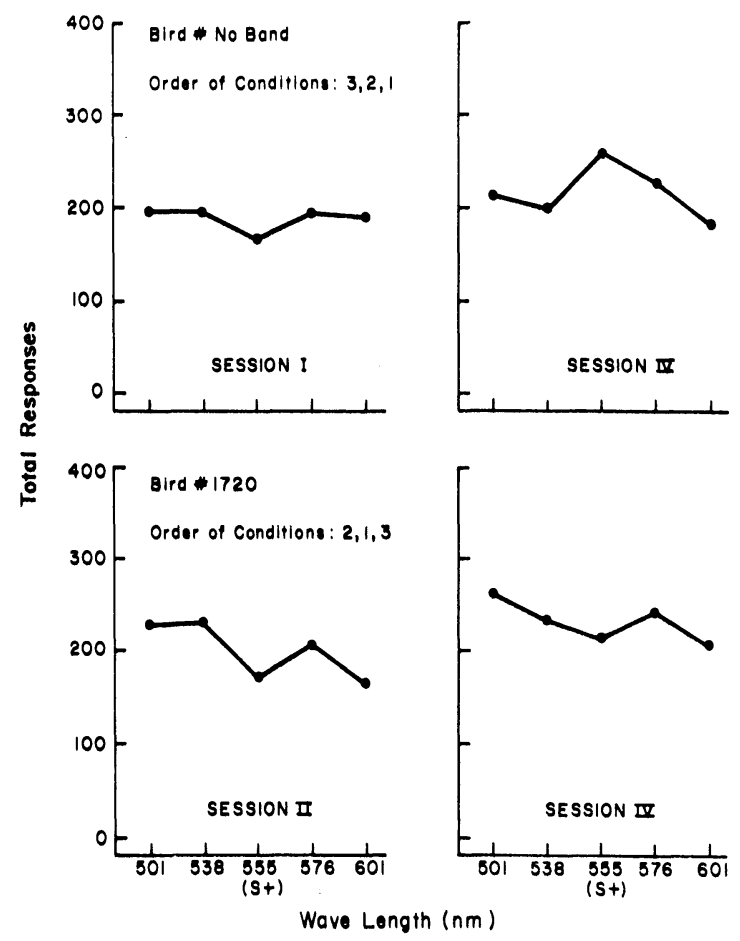

Fig. 4. Representative generalization gradients generated when responding to all stimuli is reinforced, and this condition has been preceded by conditions in which $S+$ has been nonreinforced, or both nonreinforced and punished by $7 \mathrm{sec}$ of S-.
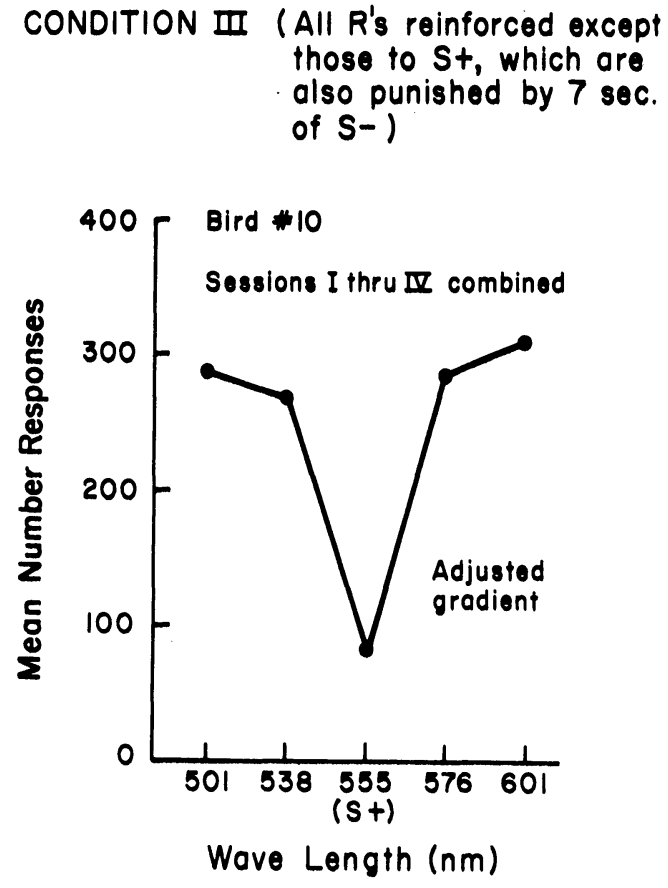

Fig. 5. An adjusted gradient for Pigeon 10 when $\mathrm{S}+$ was both nonreinforced and punished with $7 \mathrm{sec}$ of $S-$, and all other responding was reinforced on VI $30 \mathrm{sec}$ for all four testing sessions combined.

side of $\mathrm{S}+$ are elevated in Conditions II and III with respect to $S+$, because they were directly reinforced and $\mathrm{S}+$ was not, is roughly equivalent to the degree to which $\mathrm{S}+$ is elevated over the adjoining stimuli in the inverted v-shaped gradient of Fig. 1 when Condition I was not preceded by any other testing condition. That is, if this elevation, based on the mean elevation of $\mathrm{S}+$ over the adjacent points on both sides of $\mathrm{S}+$ for the first three sessions (Fig. 1), is subtracted from the adjacent points by adding this value to $\mathrm{S}+$, as was done in Figs. 2 and 5 , an adjusted gradient is derived. It is important to note that the resultant $\mathrm{v}$-shaped gradients are still quite steep.

Although most of the v-shaped inhibitory gradients do not show the expected graduated change from adjacent points to end points, it should be pointed out that inhibitory gradients obtained by more conventional means often have the same abrupt shape (Weisman, 1970).

\section{REFERENCES}

Guttman, N., \& Kalish, H. I. Discriminability and stimulus generalization. Journal of Experimental Psychology, 1956, 51, 79-88.

Hearst, E., Besley, S., \& Farthing, G. W. Inhibition and the stimulus control of operant behavior. Journal of the Experimental Analysis of Behavior, 1970, 14, 373-409.

Weisman, R. G. Factors influencing inhibitory stimulus control: Differential reinforcement of other behavior during discrimination training. Journal of the Experimental Analysis of Behavior, 1970, 14, 87-91.

(Received for publication February 27, 1974.) 